Проблеми математичного моделювання та теорії диференціальних рівнянь

УДК 539.3

\title{
ПОЧАТКОВО-КРАЙОВА ЗАДАЧА ВИЗНАЧЕННЯ ДИНАМІЧНИХ НАПРУЖЕНЬ У ШАХТНИХ ПІДЙОМНИХ МЕХАНІЗМАХ, З УРІВНОВАЖЕНИМ ГОЛОВНИМ КАНАТОМ
}

${ }^{*}$ Т. С. Зеленська, ${ }^{* *}$ А. В. Сясєв

* Дніпропетровсъкий начіональний університет ім. Олеся Гончара, кафедра диференціальних рівнянь, вул. Казакова, 18/14, ДНУ, 49010, Дніпропетровсък, E-mail: tanyazese@yandex.ru

** Дніпропетровсъкий начіональний університет ім. Олеся Гончара, кафедра диференціальних рівнянь, вул. Казакова, 18/14, ДНУ, 49010, Дніпропетровсък, E-mail: syasev@i.ua

Розглянуто постановку крайової задачі для сталевого каната підйомної установки. Знайдено розв'язок початково-крайової задачі для пружної нитки як області з рухомою границею. Наведено програмну реалізацію результатів впливу відображених хвиль на напруження в перетинах каната.

Ключові слова: напруження, метод продовження, хвильове рівняння, врівноважений канат.

\section{1. Вступ}

Для гарантування безпечної роботи стаціонарної канатної підйомної установки у всіх технічно можливих виробничих ситуаціях на діючих стовбуpax шахт і рудників необхідно знати основні залежності між амплітудночастотними динамічними характеристиками поздовжніх коливань каната, режимними та інерційними параметрами підйомної установки. Незважаючи на досить велику кількість досліджень у цій галузі, проведених для стаціонарних установок, ряд задач, характерних для дослідження напружень у перетинах каната за допомогою модифікованого методу продовження, на цей час не мають явного розв'язку. Дослідження в цій сфері проводилися О. А. Горошком, Г. М. Савіним, Ф. В. Флоринським, В. А. Остапенком, Л. В. Колосовим, В. І. Дворніковим, О. М. Обуховим та ін. Але з удосконаленням стаціонарних підйомних установок виникла необхідність у додатковому дослідженні ïх динамічних характеристик, таких як пружні переміщення і напруження, враховуючи відповідні режими руху системи. У працях Л. В. Колосова, Т. І. Жигули, В. А. Пристрома в математичних моделях не враховувався спільний взаємовплив поздовжніх коливань гілки каната із зустрічними відображеними та залишковими хвилями від рухомого кінця (точка дотику каната з барабаном намотування). Практика експлуатації канатних вантажопідйомних

(C) T. С. Зеленська, А. В. Сясєв, 2013 
машин і транспортерів показала, що найбільш уразливою є зона намотування тягового і вантажопідйомного канатів на барабани привода [2]. У цій зоні, крім напружень розтягування в канаті й намотаної частини каната на барабані, виникають значні знакозмінні контактні і дотичні напруження, які спричинюють руйнування каната, як у точці зіткнення з барабаном, так i в різних перетинах висячого каната з вантажем, і значно зменшують довговічність роботи машини в цілому. Задачі про поздовжні коливання каната безпосередньо пов' язані з дослідженням динамічного напруження в шахтних канатних ліфтах.

Велика кількість публікацій присвячена дослідженню даної проблеми, проте відмінною рисою цих досліджень є той факт, що розглядаються тільки канати постійної довжини. Тобто зміна довжини, по суті, не враховуеться, зокрема в період підйому та опускання вантажу. Тому в подібних працях не акцентується увага на особливості руху хвиль у середовищі зі змінними границями, отже, їх результати суттєво спотворюють реальну картину розподілу динамічного поля напружень. Подібна неточність у вихідній постановці задачі викликала необхідність уводити підвищені значення коефіцієнтів запасу міцності. Наслідком такого підходу було значне погіршення конструкції і підвищення витрат енергії на одиницю переміщення вантажу.

О. I. Ішлинський, I. Г. Пановко все ж ураховували при розгляді подібних проблем зміну довжини каната в часі. Відмінною рисою подібних робіт було використання методу розподілу змінних для розв'язання початково-крайових задач зі змінними границями. Проте в крайових задачах, що описують процеси поширення хвиль в канатах змінної довжини, не застосовувався безпосередньо до побудови відображених і залишкових хвиль принцип розподілу змінних. Тому такі початково-крайові задачі були перетворені на інтегральнодиференціальні рівняння зі змінними границями інтегрування (А. А. Чиж, Г. М. Савін, О. А. Горошко). I знову-таки, наближені розв'язки інтегральнодиференціальних рівнянь були побудовані за допомогою методу розподілу змінних. У цих працях були використані наближені асимптотичні методи, що дозволяють спостерігати напруження в канаті в цілому, але при малих швидкостях, і тільки для однієї вибіркової точки на канаті.

При оцінці точності використаних вищеперерахованих методів були виявлені великі похибки у зв' язку з використанням в обчисленнях тільки функцій, що задаються в дискретній формі. Строго кажучи, інтегрально-диференціальні рівняння зі змінними границями інтегрування не мають простих власних функцій. Тому спільне розв'язування виконувалося на власних функціях спрощених операторів [2]. Відповідно, були зроблені деякі спрощення: інтегрально-диференціальне рівняння для каната змінної довжини за умови, що швидкість зміни довжини каната невелика, було замінено рівнянням для каната постійної довжини, і загальний розв'язок було отримано на простих функціях останнього рівняння (А. Г. Роздольський, Ю. В. Заболотний). Також були отримані асимптотичні оцінки до даного підходу [3]. Однак вони показують тільки, що зміна довжини каната прагне до зменшення, в результаті 
обнуляється, тобто довжина каната не змінюється, і розв'язки для канатів із змінною і постійною довжиною збігаються в певних межах.

Недоліком цих розв'язків є те, що за їх допомогою важко зрозуміти характер переміщення і взаємодії хвиль в канаті з моменту початку намотування каната на барабан і до повної зупинки підйомної машини. Вищезазначені способи вирішення даної проблеми зумовлюють необхідність докладного аналізу процесу розповсюдження хвиль у сталевих канатах і стержнях змінної довжини. Це можливо тільки якщо брати до уваги зміни їх довжини і застосовувати метод відображення та продовження для врахування впливу відображених хвиль. Тому в даній статті ми розглядаємо початково-крайові задачі для канатів, стержнів і струн змінної довжини. Оскільки ці проблеми досить нові, є потреба розробити метод для розв'язання такого роду задач. У нашій статті задача про поздовжні коливання сталевого каната змінної довжини приводиться до розв'язку одновимірного хвильового рівняння на інтервалі із змінною границею. А зміна в часі довжини інтервалу викликана силою, що діє у верхньому перетині каната, в точці дотику з барабаном. Наведення рівняння руху каната у формі хвильового рівняння 3 початково-крайовими умовами першого роду і змішаного типу приводять нас до використання модифікованого методу продовження і відображення, оскільки дозволяють враховувати характер відображених і залишкових хвиль від рухомого кінця. Із цього випливає, що ми можемо досліджувати показники напружень в різних перетинах каната в певний момент часу [1] і спостерігати поведінку кривої напруження за весь період роботи системи.

\section{2. Постановка задачі}

Дана стаття присвячена задачі обчислення динамічного поля переміщень i напружень у сталевих канатах змінної довжини шахтних підйомних механізмів; канати є врівноваженими, і головний канат переносить зосереджене навантаження, яке до початку руху системи перебуває на нижньому кінці головного каната (рис. 1), угору. Розглянемо випадок одновантажної підйомної установки з одним головним канатом, причому до початку намотування вантаж уже був підвішений і закріплений до нижнього кінця, який будемо вважати нерухомим у рухомій системі координат.

Тоді, відповідно, верхній кінець головного каната (точка дотику каната 3 барабаном) буде змінною границею, і змінюватиметься за визначеним наперед заданим законом. Надалі в нашій задачі ми будемо розглядати тільки частину установки: головний канат і закріплений на нижньому кінці вантаж. I будемо шукати переміщення та напруження в перетинах каната на різних режимах роботи системи.

Перед початком руху канат не провисає, встановилися статичні переміщення $u(\xi)$ та напруження $\sigma(\xi)$, де $\xi$ - вісь, яка направлена вниз, уздовж каната; $\xi=0$ - точка дотику каната з барабаном. Канат розглядається як 
пружна нитка, тобто напруження вигину в канаті набагато менше, ніж напруження розтягу нитки (тому першим можна знехтувати).

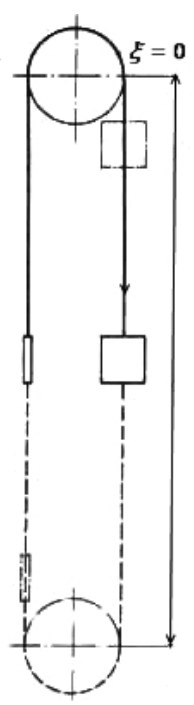

Рис. 1: Підйомна установка

Канат намотується на барабан радіусом $R$. Оскільки напруження вигину не враховується, канат можна вважати прямолінійним.

Додатний напрям пружних переміщень в канаті, які позначені $u(x, t)$, будемо вважати збіжним з додатним напрямом осі $\xi$.

Таким чином, у відносному русі розглядається частина системи, яка являе собою стержень початкової довжини $l$, обмежений на інтервалі $0<x \leq l$, причому точка $x=0$ рухається за законом

$$
\nu(t)=R \int_{0}^{t} \int_{0}^{s} \beta(\tau) d \tau d s+R \omega(0) t+\nu(0),
$$

де $R$ - середній радіус намотки каната на барабан; $\beta(t)$ - кутове прискорення барабана;

$\omega(t)$ - кутова швидкість;

$S$ - площа поперечного перетину каната.

\section{3. Розв'язання задачі}

Розглянемо підзадачу, в якій будемо уявляти канат як пружний стержень, та знайдемо розв'язок наступної крайової задачі у відносній системі координат:

в області $0+\nu(t)<x<l, \quad t>0$ знайти розв'язок хвильового рівняння

$$
\frac{\partial^{2} u}{\partial x^{2}}-\frac{1}{a^{2}} \frac{\partial^{2} u}{\partial t^{2}}=0
$$

де $a-$ швидкість звуку в стальному канаті; задовольняе наступним початковим умовам:

$$
u(x, 0)=0 ; \quad u_{t}(x, 0)=0 ; \quad 0<x<l
$$

та крайовим умовам

$$
u(l, t)=0 ; \quad u(\nu(t), t)=\mu(t) ; \quad t>0 .
$$

При $t=0$ довжина пружної стальної нитки (канат) дорівнює $l$, при $t>0$ незакріплений кінець даного інтервалу зображуємо функцією $x=\nu(t), \quad \nu(0)=0$.

Розв'язок шукаємо у вигляді:

$$
u(x, t)=\chi(x-a t)+\chi(x+a t) .
$$


Оскільки один кінець закріплений, то

$$
u(x, t)=\chi(x-a t) .
$$

Побудуємо продовження функції $\mu(t)$ на всю вісь $t$

$$
\tilde{\mu}(t)=\left\{\begin{array}{l}
\mu(t), \quad t \geq 0 \\
0, \quad t<0
\end{array}\right.
$$

Враховуючи продовження (3.5) та другу крайову умову (3.3), підставляємо у форму розв'язку (3.4)

$$
\chi(\nu(t)-a t)=\tilde{\mu}(t)
$$

Виконаємо заміну

$$
z=\nu(t)-a t
$$

Будемо вважати, що функція $\nu(t)$ неперервно диференційовна при $t>0$, тоді:

$\nu(t)-a t<0, \quad \nu(t)<a t, \quad\left|\frac{d \nu}{d t}\right|<a, \quad\left|\nu^{\prime}(t)\right|<a, \quad(\nu(t)-a t)^{\prime}=\frac{d \nu}{d t}-a<0$.

Для того, щоб дана задача була розв'язною, необхідне існування оберненої функції $t_{0}(z)$ до перетворення $z$. Приймемо, що поздовжні хвилі в пружному стальному канаті розповсюджуються з дозвуковою швидкістю, і тоді функція $t_{0}(z)$ буде монотонно спадною відносно $z$.

Застосовуючи метод продовження, будуємо продовження на всю вісь $z$ функції $t_{0}(z)$ :

$$
\begin{gathered}
t_{0}(z)=\left\{\begin{array}{cc}
<0, & z>0 \\
=0, & z=0 \\
>0, & z<0
\end{array}\right. \\
z \equiv \nu\left(t_{0}(z)\right)-a t_{0}(z) \\
t \equiv t_{0}(\nu(t)-a t) \\
\mu\left(t_{0}(z)\right)=\chi(z) .
\end{gathered}
$$

Враховуючи властивості оберненої функції, побудуємо продовження для функції $\tilde{\mu}(t)$ :

$$
\tilde{\mu}\left(t_{0}(x-a t)\right)=\tilde{\mu}(t)=\left\{\begin{array}{l}
\mu(t), \quad t>0, \quad x-a t<0, \quad t>\frac{x}{a}, \quad x<a t \\
0, \quad t<0, \quad x-a t>0, \quad t<\frac{x}{a}, \quad x>a t .
\end{array}\right.
$$

Функція 


$$
u(x, t)=\tilde{\mu}\left(t_{0}(x-a t)\right)=\tilde{\mu}(t)=\mu(t)
$$

при $t>0$ та $t<\frac{l}{a} \in$ розв'язком рівняння (3.1). Для того, щоб функція $u(x, t)$ задовольняла всім початковим та крайовим умовам у постановці задачі на більшому інтервалі, розглянемо суперпозицію хвиль, що випромінюються рухомим кінцем, та відображеної від нерухомого кінця:

$$
u(x, t)=\tilde{\mu}\left(t_{0}(x-a t)\right)-\tilde{\mu}\left(t_{0}(2 l-(x+a t))\right) .
$$

При $0<t<\frac{2 l-\nu(t)}{a}$ функція (3.9) є розв'язок рівняння (3.1), і задовольняє початковим умовам (3.2) та крайовим умовам (3.3).

При $t>\frac{2 l-\nu(t)}{a}$ у функцію (3.9) вводимо третій доданок $\tilde{\mu}\left(t_{0}(x-a t-\right.$ $(3 l-2 \nu(t))))$ як додаткову функцію. Однак остання функція не задовольняє рівнянню (3.1), оскільки $x=3 l-2 \nu(t) \in$ рухомою точкою, отже, джерело не миттєве, і в розв'язок вносяться деякі уточнення.

Для того щоб знайти розв'язок задачі на більшому інтервалі методом продовження, потрібно відшукати найменший додатний корінь $\tau_{1}$ для рівняння $a t=2 l-\nu(t)$. Таким чином в області $t>\tau_{1}, 0<x<\nu(t)$ знайти розв'язок рівняння (3.1), яке задовольняє відповідно таким початковим та крайовим умовам:

$$
\begin{gathered}
u\left(x, \tau_{1}\right)=0 ; \quad u_{t}\left(x, \tau_{1}\right)=0 ; \quad 0<x<\nu\left(\tau_{1}\right), \\
u(l, t)=0 ; \quad u(\nu(t), t)=f(t) ; \quad t>\tau_{1},
\end{gathered}
$$

де

$$
f(t)=\tilde{\mu}\left(t_{0}(2 l-\nu(t)-a t)\right) .
$$

Продовження функції $f(t)$ на всю вісь $t$ побудуємо таким чином:

$$
\tilde{f}(t)= \begin{cases}f(t), & t>\tau_{1}, \\ 0, & t<\tau_{1} .\end{cases}
$$

Далі, аналогічно до побудови розв'язку на попередніх інтервалах, будемо мати:

$$
u(x, t)=\chi(x-a t), \quad \chi(\nu(t)-a t)=\tilde{f}(t), \quad \chi(z)=\tilde{f}\left(t_{0}(z)\right) .
$$

Тоді розв'язок допоміжної задачі запишемо так:

$$
u(x, t)=\tilde{f}\left(t_{0}(x-a t)\right) .
$$

Очевидно, що для всіх $x$, що задовольняють $0<x<\nu(t)$, буде справедливою нерівність $x-a t<x<\nu(t)-a t$, та в силу строго монотонного спадання функції $t_{0}(z)$ та властивостей її продовження на всю вісь $t$, буде справедливим наступне співвідношення: 


$$
t_{0}(x-a t)<t_{0}(\nu(t)-a t)=t .
$$

Для $t>\tau_{1}$, очевидно, справедливою буде нерівність

$$
a t<2 l-\nu(t),
$$

або

$$
a t+\nu(t)-l<l .
$$

Враховуючи попередньо наведені нерівності, функцію (3.14) можна записати в еквівалентному вигляді:

$$
u(x, t)=\tilde{\mu}\left(t_{0}\left(2 l-\nu\left(t_{0}(x-a t)-a t_{0}(x-a t)\right)\right)\right) .
$$

Тоді

$$
\begin{aligned}
& u(x, t)=\tilde{\mu}\left(t_{0}(x-a t)\right)-\tilde{\mu}\left(t_{0}(2 l-(x+a t))\right)+ \\
& +\tilde{\mu}\left(t_{0}\left(2 l-\nu\left(t_{0}(x-a t)-a t_{0}(x-a t)\right)\right)\right)- \\
& -\tilde{\mu}\left(t_{0}\left(2 l-\nu\left(t_{0}(2 l-(x+a t))-a t_{0}(2 l-(x+a t))\right)\right)\right)
\end{aligned}
$$

буде розв'язком рівняння (3.1) і задовольнятиме початковим умовам (3.2) та крайовим умовам (3.3) при

$$
t<\frac{4 l-\nu(t)-2 \nu\left(\tau_{1}\right)}{a} .
$$

Оскільки

$$
a \tau_{1}=2 l-\nu\left(\tau_{1}\right)
$$

і враховуючи нерівність (3.16), будемо мати таке співвідношення:

$$
a t<2 a \tau_{1}-\nu(t) ; \quad a t-l+\nu(t)<2 a \tau_{1}-l .
$$

3 рівності (3.17) випливає, що $a \tau_{1}+l-\nu\left(\tau_{1}\right)=2 a \tau_{1}-l$, звідки, враховуючи $(3.4)$

$$
t_{0}\left(2 a \tau_{1}-l\right)=\tau_{1} .
$$

В силу строго монотонного спадання функції $t_{0}(z)$ і враховуючи співвідношення (3.18),

$$
t_{0}\left(t_{0}(\nu(t)-a t)-\nu\left(t_{0}(\nu(t)-a t)\right)\right)<0 .
$$

Тобто останній доданок у формулі (3.15) при $x=\nu(t)$ обертається на нуль при всіх $t$, для яких справедлива нерівність (3.16). Для всіх $t>0$ остаточний 
розв'язок рівняння

$$
\begin{aligned}
& u(x, t)=\sum_{k=2}^{\infty} \tilde{\mu}\left(t_{0}\left(w_{1}\left(w_{2}\left(\ldots\left(w_{k-2}(x-a t)\right)\right)\right)\right)\right)- \\
& -\sum_{k=2}^{\infty} \tilde{\mu}\left(t_{0}\left(w_{1}\left(w_{2}\left(\ldots\left(w_{k-2}(2 l-(x-a t))\right)\right)\right)\right),\right.
\end{aligned}
$$

де $w(y)=2 l-\left(\nu\left(t_{0}(y)\right)+a t_{0}(y)\right)$.

При $k=2$ обидва члени ряду (3.19) мають вигляд $\tilde{\mu}\left(t_{0}(x-a t)\right)$ або $\tilde{\mu}\left(t_{0}(2 l-\right.$ $(x+a t)))$ відповідно.

Нехай $\tau_{n}, \quad n=1,2, \ldots \in$ найменшим додатним коренем рівняння

$$
a t=a \tau_{n-1}+2 l+\nu\left(\tau_{n-1}\right)+\nu(t),
$$

тоді $t$ буде задовольняти такій нерівності:

$$
\tau_{n-1}<t<\tau_{n}-\frac{l+\nu\left(\tau_{n}\right)}{a}, \quad n=1,2, \ldots .
$$

Якщо $\tau_{0}=0$, то

$$
a t=2 n l+2 \sum_{k=0}^{n-1} \nu\left(\tau_{k}\right)+\nu(t) .
$$

Отже, сумування ряду (3.19) з функціями аргументу $\tilde{\mu}\left(t_{0}(2 l-(x+a t))\right)$ достатньо здійснювати до $k=n$.

Повернемось до побудови відображених хвиль за рисунком 2. Використовуючи метод продовження відображених хвиль, як показано вище, знайдемо розв'язок рівняння (3.1) з урахуванням крайових умов у точці намотки на барабан, тобто, використовуючи принцип суперпозиції, наведемо розв'язок даної задачі у вигляді суми функцій:

$$
u(x, t)=u_{1}(x, t)+u_{2}(x, t)+u_{3}(x, t),
$$

причому функція $u_{1}(x, t)$ визначається виразом (3.19).

Кожна $з$ функцій $u_{i}(x, t)$ повинна в області $\nu(t)<x<l, t>0$ задовольняти хвильовому рівнянню (3.1). Функція $u_{2}(x, t)$ також задовольняє відповідно початковим та крайовим умовам

$$
\begin{gathered}
u(x, 0)=0 ; \quad u_{t}(x, 0)=0 ; \quad 0<x<l ; \\
u(\nu(t), t)=-\tilde{u}(\nu(t)) ; \quad u_{x}(l, t)=0 ; \quad t>0,
\end{gathered}
$$

де $\tilde{u}(x)=\frac{G}{E S} E+\frac{\lg x}{a^{2}}-\frac{g x^{2}}{2 a^{2}}-$ частинний розв' язок крайової задачі про пружні переміщення точок каната у відносному русі; $G=m g, E$ - модуль пружності 
першого роду. Отже, неоднорідні крайові умови для функції $u_{2}(x, t)$ враховують той факт, що в канаті існують переміщення $\tilde{u}(\nu(t))$, створені функцією $u(\xi)=\frac{G}{E S} \xi+\frac{\lg \xi}{a^{2}}-\frac{g \xi^{2}}{2 a^{2}}$.

Функція $u_{3}(x, t)$ повинна задовольняти початковим (3.21) та крайовим умовам

$$
u(\nu(t), t)=0 ; \quad u_{x}(l, t)=\gamma\left(-R \beta(t)+\frac{\partial^{2} u_{1}(l, t)}{\partial t^{2}}+\frac{\partial^{2} u_{2}(l, t)}{\partial t^{2}}\right) H(t), \quad t>0,
$$

де $H(t)$ - функція Хевісайда; $\gamma=\frac{m}{E S}$.

Тобто функція $u_{3}(x, t)$ враховує, що прискорення $\beta(t)$ виникає тільки в момент пуску намотувального барабана.

Розв' язок для кожної з функцій $u_{2}(x, t)$ та $u_{3}(x, t)$ шукається за аналогією із запропонованим методом допоміжної підзадачі для функції $u_{1}(x, t)$.

У результаті ми можемо побудувати динамічні поля переміщень та напружень для будь-якої точки каната, включаючи точку дотику каната з барабаHOM.

\section{4. Чисельна реалізація крайової задачі}

Із метою зменшення капітальних затрат та скорочення строків зупинки при зношуванні стальних канатів під час підйому вантажів ми чисельно визначили показники напружень в будь-який момент часу роботи шахтної установки. Для розрахунків нами були використані згладжені діаграми швидкості, отримані на практиці під час роботи підйомної машини в діючих стовбурах С. Р. Ільїним.

Дана залежність швидкості підйому вантажу головним канатом від часу роботи установки була нами взята з праці С. Р. Ільїна [2], ІГТМ НАН України. Тобто подальша числова реалізація пошуку переміщення та напруження в канаті в точці дотику його з барабаном $є$ досить чіткою та відповідає дійсним природним умовам робочого використання подібних шахтних машин. Згладжена діаграма швидкості була отримана на основі аналізу експериментальних даних, отриманих у промислових умовах із використанням спеціалізованої вимірювальної апаратури. Отже, за допомогою степінної інтерполяції знаходимо аналітичний вид функції переміщення точки дотику каната з барабаном, попередньо знайшовши відповідні дискретні значення оберненої функції до швидкості переміщення.

Відобразимо згладжену діаграму швидкості, враховуючи чисельну побудову модифікованого методу відображення для відбитих хвиль (рис. 2). Враховуючи постановку хвильового рівняння (3.1) та крайові умови (3.3), побудуємо криву переміщення точки дотику, яка буде змінюватись відповідно до характеру відображених хвиль від рухомого кінця (рис. 3). 


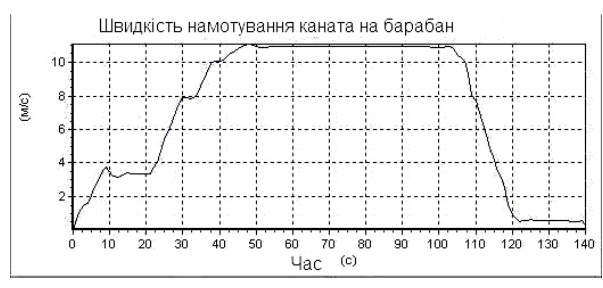

Рис. 2: Діаграма швидкості

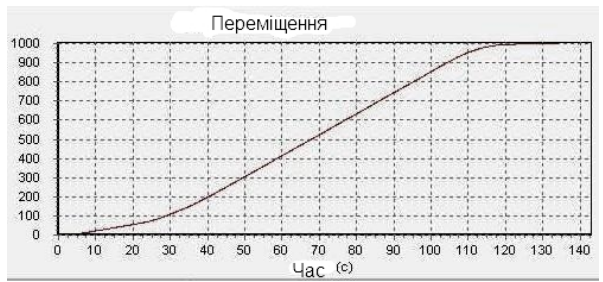

Рис. 3: Крива переміщення точки дотику

Враховуючи отриманий розв'язок для функції $u(x, t)=u_{1}(x, t)+u_{2}(x, t)+$ $u_{3}(x, t)$, знайдемо для кожного моменту часу роботи підйомної канатної установки відповідні показники кутового прискорення барабана:

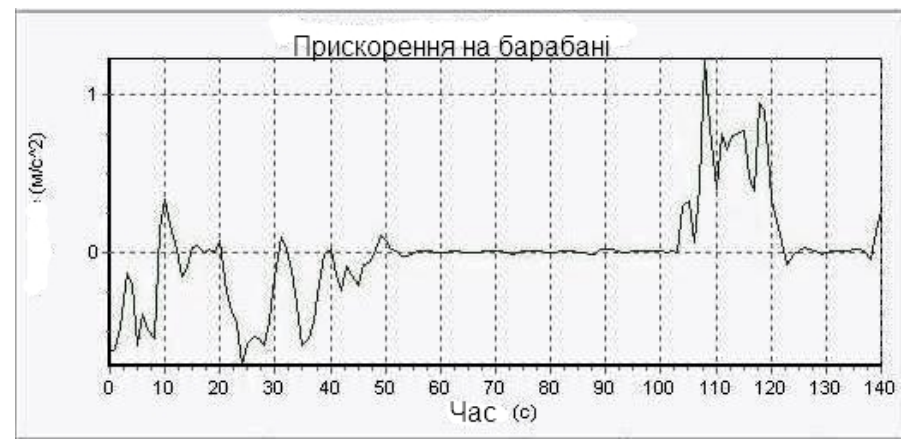

Рис. 4: Кутова швидкість

У підсумку, завдяки залученню експериментальних промислових даних до обчислення полів переміщень та напружень, ми можемо спрогнозувати мінімальні та максимальні відхилення навантаження в головному канаті. Завдяки врахуванню залишкових та відбитих хвиль, що з'являються при залученні крайових умов на рухомому кінці каната, ми маємо реальний графік коливань напружень в канаті в природних умовах.

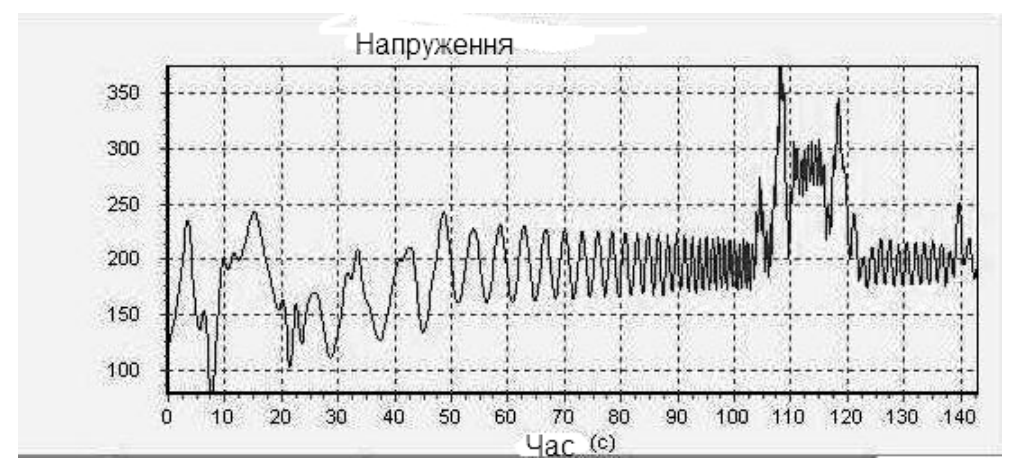

Рис. 5: Поле напружень 
У табличній формі продемонструємо точкові значення напружень в різні періоди роботи системи:

\begin{tabular}{|c|c|c|c|}
\hline $\begin{array}{l}\text { Час } \\
\text { pyxy, } \\
\text { сек })\end{array}$ & $\begin{array}{l}\text { Напруження, } \\
\text { метод продов- } \\
\text { ження }\end{array}$ & $\begin{array}{l}\text { Напруження, } \\
(\mathrm{H}), \\
\text { метод Рунге } \\
- \text { Кутта }\end{array}$ & $\begin{array}{l}\text { Різниця у фік- } \\
\text { сованих } \\
\text { точках (H). }\end{array}$ \\
\hline 0 & 0 & 0 & 0 \\
\hline 20 & 27653 & 25799 & 1854 \\
\hline 40 & 18123 & 16054 & 2069 \\
\hline 60 & 7535 & 6891 & 644 \\
\hline 80 & 5328 & 5001 & 327 \\
\hline 100 & 32567 & 29521 & 3046 \\
\hline 120 & 2121 & 1549 & 572 \\
\hline 140 & 0 & 0 & 0 \\
\hline
\end{tabular}

\section{5. Висновки}

Проведено дослідження динамічної задачі, пов'язаної з поздовжніми коливаннями канатів шахтних систем, що містять деформівні одновимірні тіла (пружні канати, стержні, балки). Отримані результати можуть бути подані у вигляді таких тез:

1. Сформульовано задачу про динаміку підйомної установки з погляду зміни напружень в перетинах каната (пружного стержня) у часі. Встановлено закономірності впливу характеру відбитих хвиль від рухомого і нерухомого кінців пружної нитки, необхідні для оптимальної роботи підйомної системи.

2. На підставі розв'язків початково-крайової задачі про рух поздовжніх коливань для області з рухомою границею встановлено закономірність зміни амплітуд основного тону коливань стержня і принципову відмінність цієї задачі від випадку крайових задач, які не враховують залишкові хвилі, що виникають при нелінійних коливаннях незакріпленої опори; а саме: в нерухомій системі при русі вздовж пружного стержня амплітуда напруження практично не змінюється, а в системі з нестійкою опорою амплітуда напруження залежить від зміни лінійного та кутового прискорень.

3. Запропоновано і чисельно реалізовано математичну модель руху вантажопідйомної установки, з урахуванням радіуса кривизни в точці дотику каната з барабаном (шківом); чисельно наведено результати амплітуди зміни переміщень і напружень в різних перетинах каната, в певний момент часу руху системи; наведено задачу динамічного поля про перемотування вагомої розтяжної нитки, вказано також дві групи початково-крайових зв'язків, необхідних для повноти постановки задачі, та отримано такі нові результати: встановлено, що коливання рухомої сталевої нитки (канат) має хвильовий, неперіодичний характер; частоти коливання нитки зменшуються зі збільшенням швидкості перемотування; має місце кінематичне деформування коливання 
нитки, зумовлене виносом енергії поздовжніх деформацій з коливальної ділянки, внаслідок впливу залишкових хвиль в області критичних напружень.

4. Досліджено закон переміщення незакріпленого верхнього кінця з урахуванням крайових умов у початковій точці намотування каната; встановлено, що вертикальні коливання несучого каната є джерелом параметричних збурень напружень по всій довжині пружної нитки. Розв'язано задачу про коливання каната підвісної системи під дією руху вантажу (закріплена границя); встановлено закони зміни амплітуди коливань каната підвісної системи під час переміщення вантажу.

\section{Бібліографічні посилання}

1. Воеводин B. В. Численные методы в прикладном пакете sage / В. В. Воеводин.Спб. : БХВ-Петербург, 2011. -257 с.

2. Ильин С. Р. Влияние параметров скорости подъема и эксцентриситета груза на динамику системы "сосуд-армировка"шахтных стволов / С. Р. Ильин // Сб. науч. тр. ИГТМ НАН Украины. -2012. -Вып. 98. - С. 322-348.

3. Ostapenko $V$. A. Dynamic field of displacements in rods of variable length/ V. A. Ostapenko // Proceedings of 8th International Conference on Dynamical Systems Theory and Applications. 2011. Lodz: 316-323. 